\title{
Purity and Stability of Online-Prepared Hemodiafiltration Fluid after Storage
}

\author{
V. Corradia, c D. Cruz ${ }^{a, c} \quad$ A. Vázquez-Rangel ${ }^{c} \quad$ F. Furlan ${ }^{b} \quad$ R. Grillone ${ }^{b}$ \\ A. Bonaccorsi ${ }^{b}$ S. Cazzavillan ${ }^{c} \quad$ M. de Cal ${ }^{a, c}$ P. Frisone ${ }^{a} \quad$ A. Moreac \\ A. Brendolan ${ }^{a} \quad$ M. Rassu ${ }^{b} \quad$ C. Ronco ${ }^{a, c}$
}

Departments of a Nephrology and ${ }^{\mathrm{b}}$ Microbiology, San Bortolo Hospital, and ${ }^{\mathrm{C}}$ International Renal Research Institute

Vicenza, Vicenza, Italy

\section{Key Words}

Acid-base balance - Continuous renal replacement therapy • Electrolyte stability · Fluid purity $\cdot$ Online hemodiafiltration fluid $\cdot$ Storage time

\begin{abstract}
Background/Aims: Previous studies have suggested that online hemodiafiltration (OL-HDF) fluid can be used as dialysate for continuous renal replacement therapies, and thus HDF costs can be reduced. The aims of this study were to determine the purity of OL-HDF fluid and to verify the stability of the electrolyte composition and acid-base balance during its storage. Methods: OL-HDF fluid was collected in 70 individual bags and stored for up to 7 days. The following tests were performed daily in 10 bags: natural visible precipitation (macrocrystallization), sample collection for chemical analysis and fluid culture, limulus amebocyte lysate endotoxin test, standard culture of NALGENE ${ }^{\circledR}$ filters after passing of the fluid, and molecular analysis of bacterial DNA. Results: The values of $\mathrm{pH}$ and $\mathrm{pCO}_{2}$ showed a significant change starting at $24 \mathrm{~h}(\mathrm{p}<0.001)$; after $72 \mathrm{~h}$, their values were beyond the measurable range. Coefficient of variation for $\mathrm{pCO}_{2}$ was as high as $25.7 \%$. Electrolyte composition $\left(\mathrm{Na}^{+}, \mathrm{K}^{+}, \mathrm{Cl}^{-}\right.$, $\mathrm{Ca}^{2+}$ and glucose) showed a statistically significant difference over time $(p<0.05)$; however, their coefficients of vari-
\end{abstract}

ation were low $(1.7,1.4,0.6,2.3$ and $0.9 \%$, respectively), which might not be considered clinically significant. Negative results were obtained at all points by fluid and filter cultures, endotoxin test and molecular analysis. No macrocrystallization was observed at any time point. Conclusions: We demonstrate the microbiological purity of OL-HDF fluid stored for up to 7 days. The electrolyte composition was stable, except for a relevant change in $\mathrm{pCO}_{2}$ and consequently in $\mathrm{pH}$ (first noted at $24 \mathrm{~h}$ ), emphasizing the need to reassess the acid-base balance in multilayer plastic bags in future studies.

Copyright $\odot 2013$ S. Karger AG, Base

\section{Introduction}

Acute kidney injury (AKI) is a common complication in hospitalized patients, with an incidence around 5\% [14]. Mortality in patients with AKI remains high, reaching up to $50 \%$ in severely ill patients [1-4].

Approximately 5-6\% of critically ill patients require extracorporeal renal support during their intensive care unit stay [4]. Continuous renal replacement therapies (CRRT) have been increasingly used in critically ill patients with AKI mainly under the statement of a better hemodynamic stability, although they result in higher costs, basically due to the extracorporeal circuit, the fil-

\section{KARGER}

Fax +4161306 1234

E-Mail karger@karger.com

www.karger.com
C 2013 S. Karger AG, Basel

$0253-5068 / 13 / 0353-0112 \$ 38.00 / 0$

Accessible online at:

www.karger.com/bpu
Claudio Ronco, MD

Department Nephrology, San Bortolo Hospital

Viale Rodolfi 37

IT-36100 Vicenza (Italy)

E-Mailcronco@goldnet.it 
ters and the required volume of replacement and dialysate fluids [5]. It has been estimated that the latter contribute to $33 \%$ of the total CRRT costs [6].

For the Beginning and Ending Supportive Therapy group, Srisawat et al. [5] have mentioned the possibility of reducing costs of CRRT by limiting the dose or the amount of fluids used to $25 \mathrm{ml} / \mathrm{kg} / \mathrm{h}$. Nevertheless an alternative approach could be the on-site production of the required fluids for this therapy.

Usually, for end-stage renal disease, online hemodiafiltration (OL-HDF) may represent one of the best therapy options with considerably lower costs of dialysate and replacement fluids compared to previous non-online production. This online technique uses ultrafilters capable of removing endotoxins and bacteria to finally mix ultrapure water with acid and bicarbonate concentrates, enabling the immediate use of a solution with a desired composition and high microbiological quality [7]. As suggested by Leblanc et al. [8], fluids produced by the dialysis machine through a cold cascade filtration could make this ultrapure solution available for use in CRRT. Their use could reduce the need for commercially produced dialysate fluids, and therefore CRRT costs.

Although previous studies using machine-prepared fluids for CRRT have randomly sampled some bags for purity control $[8,9]$, data on daily serial measurements have not been published, and consequently a time limit for their possible use has not been established. This information could guide their use in case of no in-center access to online fluids as for example in nearby second-level hospitals or during natural disasters.

Moreover, newer molecular techniques to detect the presence of microorganisms are now available to complement the experimental evaluation of the purity of this fluid, and there is also no published information about the stability of the acid-base and electrolyte composition in the stored bags over time.

The primary objective of this study was to determine the purity of prepared OL-HDF fluid and the secondary objective was to verify both the stability of the electrolyte composition and the acid-base balance during the storage of this solution.

\section{Materials and Methods}

\section{OL-HDF Fluid Preparation}

OL-HDF solution was prepared with two different dialysis machines, AK 200 ULTRA (Gambro AB, Lund, Sweden) and 4008H (Fresenius, Homburg, Germany). The solution produced was a replication of the standard fluid used during OL-HDF. These di- alysis machines use acid and bicarbonate concentrate mixed with heated water (treated by reverse osmosis in our dialysis unit). The predefined standard composition consisted of $\mathrm{Na}^{+} 138 \mathrm{mmol} / \mathrm{l}, \mathrm{K}^{+}$ $2 \mathrm{mmol} / \mathrm{l}, \mathrm{HCO}_{3}{ }^{-} 32 \mathrm{mmol} / \mathrm{l}$ and $\mathrm{Ca}^{2+} 1.5 \mathrm{mmol} / \mathrm{l}$.

\section{Fluid Collection}

The whole fluid was passed through the NALGENE ${ }^{\circledR}$ in-line microorganism filter system designed for removal of particles or microbial contaminants from liquids (Nalgene Nunc International, Rochester, N.Y., USA). The membrane of the filter (cellulose acetate) is characterized by a pore size of $0.2 \mu \mathrm{m}$ and a diameter of $47 \mathrm{~mm}$. All components of the system were sterilized by autoclave $\left(120^{\circ} \mathrm{C}\right.$ for $\left.20 \mathrm{~min}\right)$. The filter was introduced between the dialysate fluid line and the collecting bag with a sterile technique (fig. 1). Sterile 3-liter ethylvinylacetate bags (SIFEVA, Fresenius Kabi, Isola della Scala, Italy), which were normally used for total parenteral nutrition, were hermetically closed and clamped, and stored at room temperature for up to 7 days. All bags were collected at the same time and under the same conditions.

\section{OL-HDF Fluid Analysis}

A total of 70 bags were planned to be stored, using 10 bags per day for microbiological and chemical analysis (time 0, 24, 48, 72, $96,120,144$ and $168 \mathrm{~h}$ ), plus 3 extra measurements at 3,6 and $9 \mathrm{~h}$ after its collection only for chemical analysis.

The protocol for fluid analysis consisted, in the following order, of (1) assessment of daily natural visible precipitation (macrocrystallization), (2) sample collection for chemical analysis and fluid culture, and (3) passage of the total fluid remaining through the NALGENE in-line microorganism filter system to complete the microbiological (standard cultures and endotoxin test) and molecular analysis.

\section{Chemical Analysis}

The analysis for glucose, calcium, sodium, potassium and chloride were obtained by the SYNCHRON CX ${ }^{\circledR}$ System (Beckman Instruments, Fullerton, Calif., USA) using the Jaffé method. Acid-base analysis was obtained through the Rapid point $405^{\circledR}$ System (Bayer Diagnostics, Sudbury, UK), which directly determines $\mathrm{pH}$ and $\mathrm{pCO}_{2}$ using a potentiometric method, and $\mathrm{HCO}_{3}{ }^{-}$ is calculated according to the equation derived from HendersonHasselbalch as recommended by the Clinical Laboratory Standard Institute (formerly the National Committee for Clinical Laboratory Standards) [10]. For $\mathrm{pH}$, the detectable range is $6.5-7.8$ and for $\mathrm{pCO}_{2} 10-150 \mathrm{~mm} \mathrm{Hg}$.

\section{Microbiological Analysis}

Fluid cultures for aerobic and anaerobic bacteria were obtained using the BacT/ALERT ${ }^{\circledR}$ System (SA-SN; BioMèrieux, Marcy l'Etoile, France) with a colorimetric sensor, which detects microorganisms by tracking $\mathrm{CO}_{2}$ production. The BacT/ALERT is a fully automated, dual temperature system, which may be used to conduct sterility testing at $35^{\circ} \mathrm{C}$. The membranes of the filter (at T0 and for each day of storage) were placed in tryptone glucose extract agar plates (Agricons, Italy) and incubated at $22^{\circ} \mathrm{C}$ for 7 days [11-13]. Endotoxins from Gram-negative bacteria were detected and quantitated using the kinetic limulus amebocyte lysate endotoxin test (LAL Pyrotell ${ }^{\circledR}$ Single Test Vial, Associates of CAPECOD, East Falmouth, Mass., USA) [14, 15]. The Pyrotell sensitivity used for this study was $0.125 \mathrm{EU} / \mathrm{ml}$. 
Fig. 1. Schematic representation of OLHDF fluid preparation. These dialysis machines use acid (A) and bicarbonate (B) concentrate mixed with heated water $(\mathrm{C})$ treated by reverse osmosis. The resulting fluid was drained (D) and passed through the NALGENE in-line filter system (E) into sterile 3-liter ethylvinylacetate bags (F).

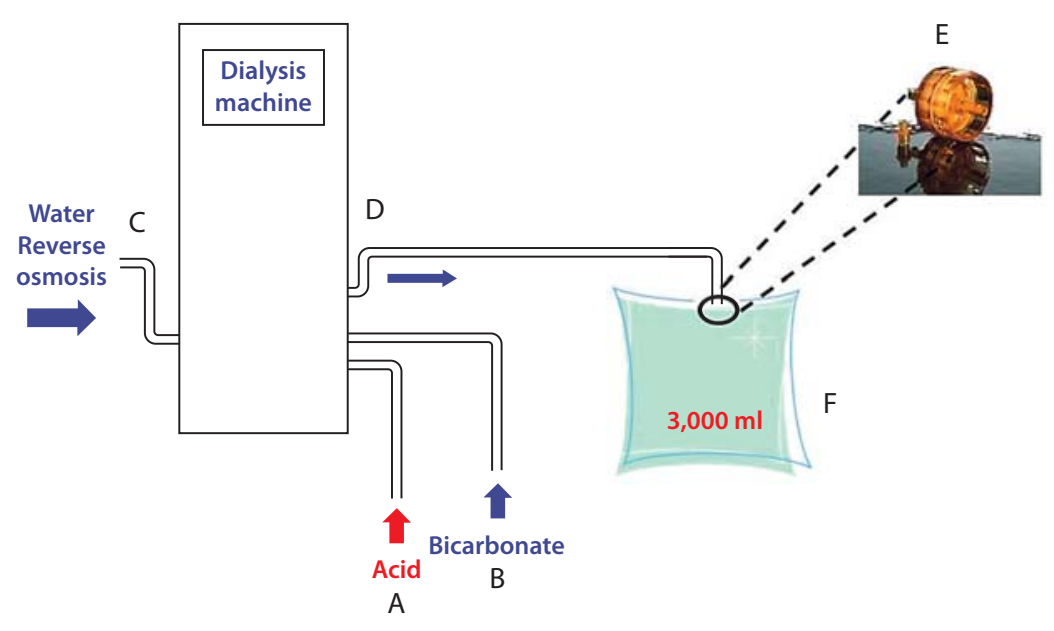

Molecular Biology Analysis

The molecular method developed for the detection and identification of bacterial DNA is based on characteristics of the bacterial 16S rRNA gene. This gene consists of highly conserved regions and mixes with highly variable regions, which allow phylogenetic analysis [16-18].

\section{Nucleic Acid Preparation}

Genomic DNAs were prepared by standard methods. Filter membrane was treated overnight in a lysis buffer containing 10 $\mathrm{mmol} / \mathrm{l}$ Tris- $\mathrm{HCl}(\mathrm{pH} 8.3$ ), $50 \mathrm{mmol} / \mathrm{l} \mathrm{KCl}$ and proteinase $\mathrm{K}$ to a final concentration of $0.5 \mu \mathrm{g} / \mu \mathrm{l}$, and Nonidet P-40 (Roche Applied Science, Mannheim, Germany) at $55^{\circ} \mathrm{C}$. After boiling and centrifugation of the solution, the supernatant was used as template.

PCR Amplification and Purification

DNA was amplified by PCR. In this study, the primers used for amplification of 16S rRNA were 355F (5'-CCTACGGGAGGCAGCAG-3') and 910R (5'-CCCGTCCATTCCTTTGAGTT$3^{\prime}$ ) [19]. Approximately $0.2-1 \mu \mathrm{g}$ of genomic DNA were amplified in a $50-\mu \mathrm{l}$ reaction. Cycler conditions consisted of $5 \mathrm{~min}$ at $95^{\circ} \mathrm{C}$, and then 35 cycles at $95^{\circ} \mathrm{C}$ for $45 \mathrm{~s}, 53^{\circ} \mathrm{C}$ for $45 \mathrm{~s}$ and $72^{\circ} \mathrm{C}$ for $45 \mathrm{~s}$. The final extension step was for $7 \mathrm{~min}$ at $72^{\circ} \mathrm{C}$. The amplification products were checked in 3\% NuSieve 3:1 agarose (Cambrex Bio Science, Rockland, Me., USA) with 5\% GelStar staining (Cambrex) using standard techniques. The PCR products were excised from gel and purified with Wizard SV Gel and PCR Clean-Up System (Promega Corp., Madison, Wisc., USA).

\section{Sequencing}

Direct Sanger sequencing was performed using the BigDye terminator v1.1 cycle sequencing kit (Applied BioSystems, Foster City, Calif., USA). The reaction products were purified with Centri-Sep Columns (Princeton Separation, Adelphia, N.J., USA) to remove unincorporated dye terminators. The sequences were determined by fluorescent capillary electrophoresis (ABI PRISM
310 Genetic Analyzer, Applied BioSystems) and then compared with a database library on the GenBank web site (http://www. ncbi.nlm.nih.gov/blast).

Positive Control for Microbiology and Molecular Analysis

The same microbiological and molecular analysis was performed in 4 positive control commercial bags, by adding $0.5 \mathrm{Mc}$ Farland $(0.125$ optic density at $550 \mathrm{~nm}$; bacterial concentration $150 \times 10^{6} / \mathrm{ml}$ ) of 4 different microorganisms (Escherichia coli, Staphylococcus aureus, Pseudomonas aeruginosa and Candida albicans).

\section{Statistical Analysis}

The continuous variables were expressed as medians (25-75th percentiles) or means \pm SE. Categorical variables were described as proportions. Kolmogorov-Smirnov and Shapiro-Wilk normality tests were used. Continuous variables were analyzed with ANOVA for repeated measurements or the Friedman test. Contrast analysis was performed to identify the changing point along time. Coefficients of variation were reported to compare changes among all chemical parameters. Values of $\mathrm{p}<0.05$ were regarded as statistically significant.

\section{Results}

Visible precipitation of all bags was not present at any time (T0-T168).

\section{OL-HDF Fluid: Chemical Analysis}

At the time of fluid production (T0), the mean values of $\mathrm{pH}, \mathrm{pCO}_{2}$ and $\mathrm{HCO}_{3}{ }^{-}$were $7.46 \pm 0.01,46.92 \pm 1.14$ $\mathrm{mm} \mathrm{Hg}$ and $32.54 \pm 0.32 \mathrm{mmol} / \mathrm{l}$, respectively. The median values of the electrolyte composition of the 
Fig. 2. Acid-base composition of OL-HDF fluid ( $\mathrm{pH}, \mathrm{pCO}_{2}$ and $\mathrm{HCO}_{3}{ }^{-}$) from $\mathrm{T} 0$ to T96. All values of $\mathrm{pH}$ and $\mathrm{pCO}_{2}$ were out of range (box plot with means, SE and ranges).

Fig. 3. Electrolyte composition of OL-HDF fluid ( $\mathrm{Na}+, \mathrm{K}+, \mathrm{Cl}^{-}, \mathrm{Ca}^{2+}$ and glucose) from T0 to T96 (box plot with medians, 25th75 th percentiles and ranges).
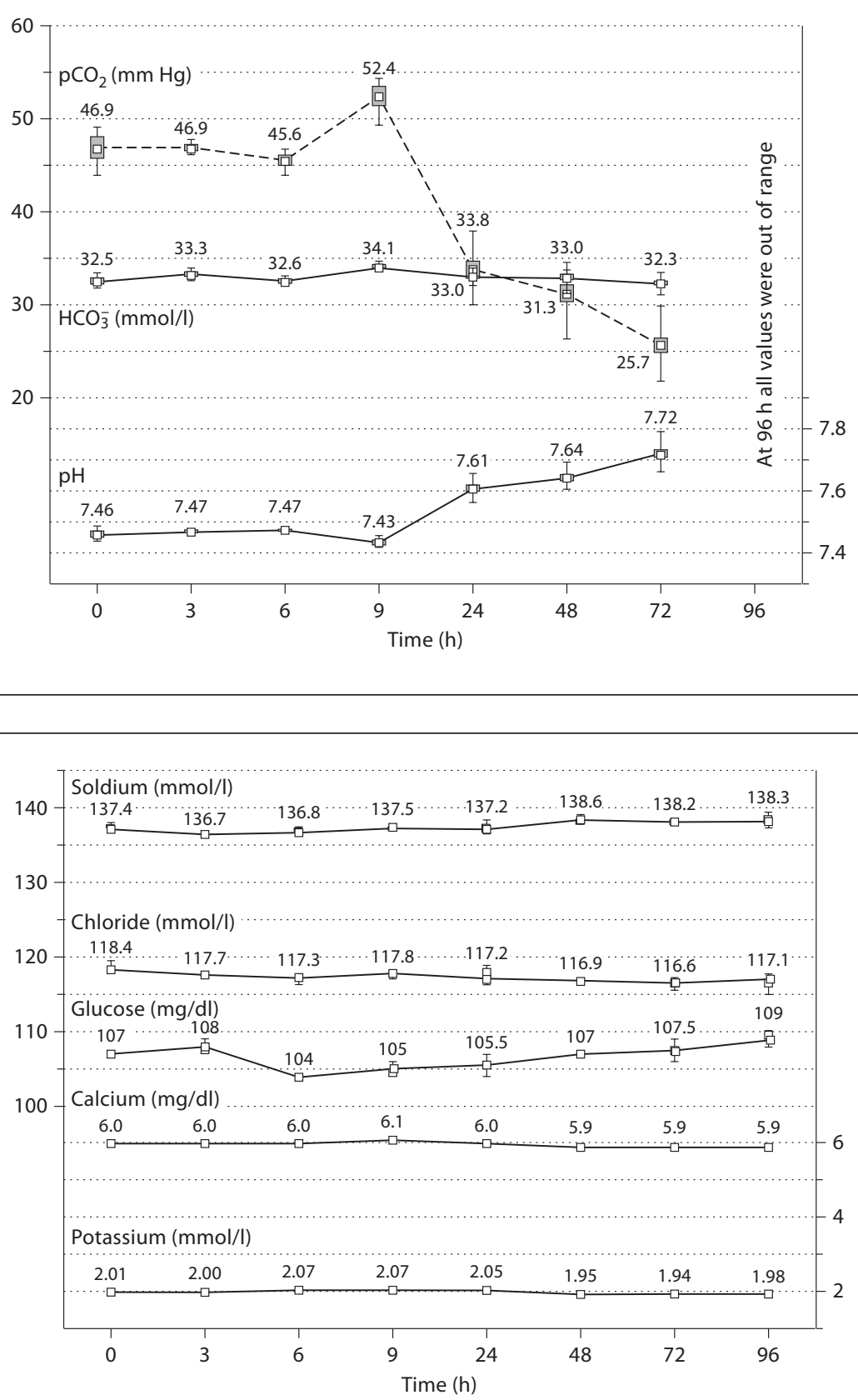

OL-HDF fluid were $\mathrm{Na}^{+} 137.4$ (137.4-137.7) mmol/l, $\mathrm{K}^{+}$ $2.01(2.01-2.02) \mathrm{mmol} / \mathrm{l}, \mathrm{Cl}^{-} 118.4(118.1-118.8) \mathrm{mmol} / \mathrm{l}$, $\mathrm{Ca}^{2+} 6.0(6.0-6.0) \mathrm{mg} / \mathrm{dl}$ and glucose 107.0 (107.0-107.0) $\mathrm{mg} / \mathrm{dl}$.

The values of $\mathrm{pH}$ and $\mathrm{pCO}_{2}$ were outside the range starting from T96. Statistical analysis of T0-T72 showed a significant change over time $(p<0.001)$. Contrast analysis showed that values differed starting from T24 (fig. 2).

There was a statistically significant difference in electrolyte composition over time (T0-T168) for all electrolytes $\left(\mathrm{Na}^{+}, \mathrm{K}^{+}, \mathrm{Cl}^{-}, \mathrm{Ca}^{2+}\right.$ and glucose; $\left.\mathrm{p}<0.05\right)$. Nevertheless, their coefficients of variation were 1.7, 1.4, 0.6, 2.3 and $0.9 \%$, respectively, compared to a coefficient of vari- 
Fig. 4. Standard cultures of the filter membranes after 7 days of incubation. a Stored OL-HDF fluid with no microbial growth (negative result). b Positive control.

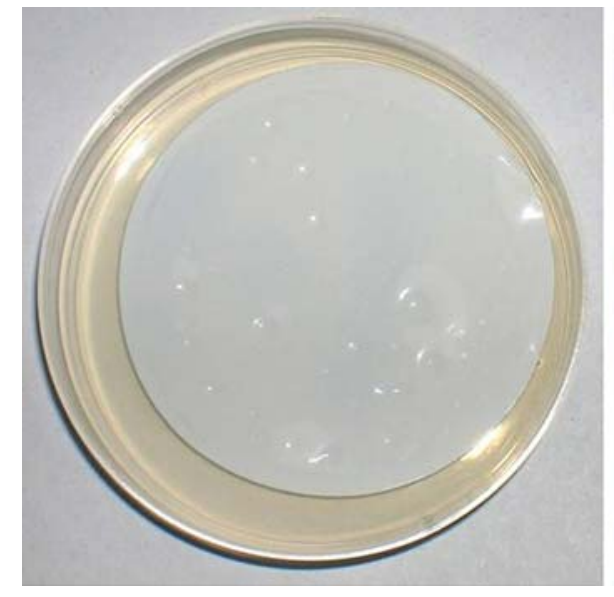

a

Negative result

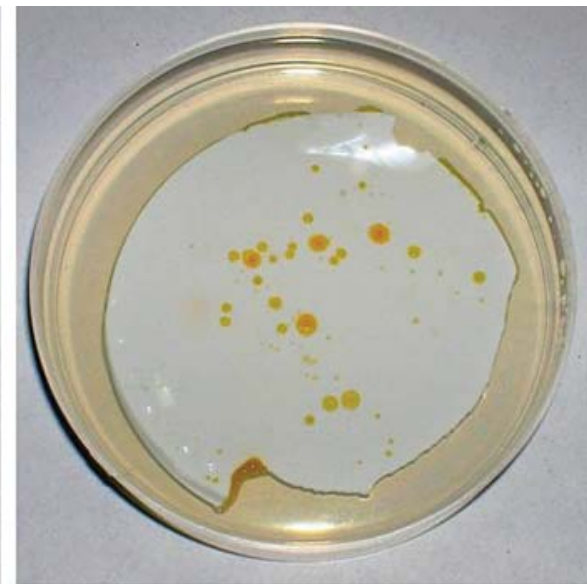

b
Positive control ation of $25.7 \%$ for $\mathrm{pCO}_{2}$. Figure 3 shows their pattern up to $96 \mathrm{~h}$ just for comparison purposes with acid-base balance.

\section{OL-HDF Fluid: Microbiological and Molecular Biological Analysis}

The BacT/Alert ${ }^{\circledR}$ system did not detect any positive signal (colorimetric) in anaerobic and aerobic OL-HDF fluid cultures at any time (T0-T168). Standard cultures after 7 days of incubation for every filter membrane were free from microorganisms. Figure 4 shows a comparison with a positive control. The analysis of the endotoxin level was negative at all times (T0-T168).

In addition, bacterial DNA was never detected from the digestion of the filter membranes (T0-T168). The sequencing of the positive controls confirmed the species of inoculated microorganisms (E. coli, S. aureus, P. aeruginosa and C. albicans).

\section{Discussion}

Our study has shown that OL-HDF fluid stored for up to 7 days can maintain its purity, by recommended standards for its use as a dialysate solution. In the literature, the microbiological purity of stored OL-HDF fluid was demonstrated at the time of its production and at random measurements up to $72 \mathrm{~h}$ [8].

The dialysate required for CRRT must meet the definition of a fluid with no detectable levels of bacteria or bacterial-derived products. Their reference values for dialysate have been established in $<10 \mathrm{CFU}$ and $<0.125 \mathrm{EU} / \mathrm{ml}$, respectively $[11,20]$. These standards might be even more important if OL-HDF fluid is meant to be stored instead of immediately used. Moreover, it is extremely important to monitor its purity during the time of storage in order to exclude unnecessary complications. As a complement to the standard culture methods to determine the microbiological purity of the OL-HDF fluid, we added a specific test. A qualitative molecular biology test based on the detection of bacterial DNA confirmed the negative microbial result in every filter membrane.

It has to be mentioned that storage conditions might influence the preservation of the microbiological quality of OL-HDF fluid. This should be considered if it is planned for use as emergency treatment outside hospital facilities, e.g. during natural disasters.

Although the level of purity tested in our study does not fit the definition of ultrapurity to confirm its use as replacement fluid, it can reduce the need for dialysate bags and therefore the costs of CRRT treatment. We plan to increase the sensitivity of the microbiology analysis to determine if the OL-HDF fluid could be used as ultrapure dialysate for replacement in CRRT, too.

Dialysate solutions may vary in composition and include a buffer and electrolytes to manage acid-base disorders and ion imbalances. Teo et al. [9] demonstrated that a large number of AKI patients in the intensive care unit can be safely, effectively and economically supported with continuous hemodialysis using machine-generated bicarbonate-based dialysate. However, they did not report the electrolyte or acid-base balance stability of the OL-HDF fluid during storage. 
Our results demonstrated statistically significant differences among the concentrations of $\mathrm{Na}^{+}, \mathrm{K}^{+}, \mathrm{Cl}^{-}, \mathrm{Ca}^{2+}$ and glucose over time (fig. 3), but their coefficients of variation were considerably low, so that these differences might not be clinically significant, supporting the concept of the stability of the electrolyte composition of our OL-HDF fluid stored for up to 7 days.

In contrast, the differences among the values of $\mathrm{pH}$ and $\mathrm{pCO}_{2}$ starting from $24 \mathrm{~h}$ pointed towards a relevant aspect in the storage of the fluid. The one-layer ethylvinylacetate bags do not represent a protective barrier for $\mathrm{O}_{2}$, $\mathrm{CO}_{2}$ and ultraviolet radiation. In theory, the dispersion of $\mathrm{CO}_{2}$ and its decrement affects the balance described by the Henderson-Hasselbalch equation, and consequently reduces $\mathrm{H}^{+}$concentration and increases $\mathrm{pH}$. The values reported for $\mathrm{HCO}_{3}{ }^{-}$should ideally be verified by a quantitative technique, as ours are calculated and not directly measured from the samples. Repeating this study with next-generation multilayer ethylvinylacetate bags could prevent the loss of $\mathrm{CO}_{2}$ and therefore contribute to acidbase stability.

Finally, in previous years, the possibility of calcium carbonate precipitation prevented the widespread use of premixed fluid bags $[8,21,22]$. In our study, visual inspection was negative at all times, and no clinically significant changes in calcium or bicarbonate concentrations were noticed. Nevertheless, different predefined prescriptions for calcium levels in OL-HDF fluid (1.5 vs. 2.5 or $3.5 \mathrm{mmol} / \mathrm{l}$ ) might produce different results.
In summary, using advanced qualitative molecular biology analysis to detect bacterial DNA in addition to the standard microbiology analysis, we had demonstrated the purity of OL-HDF fluid stored in plastic bags for up to 7 days.

We verified the clinical stability of the electrolyte composition of prepared OL-HDF fluid, although a relevant change in $\mathrm{pCO}_{2}$ and consequently in $\mathrm{pH}$ was noticed starting from $24 \mathrm{~h}$, which underlines the need to reassess the acid-base balance in multilayer plastic bags.

This study represents an important step to establish a time limit for storing OL-HDF fluid for its use in CRRT and consequently paves the way for a sustainable alternative to the more expensive pharmacy-made solutions.

\section{Acknowledgment}

Dr. Armando Vázquez-Rangel has been supported by an ISNfunded fellowship program. We are thankful to Dr. Ciro Tetta for the revision of the paper. We are grateful to the laboratory technician Roberto Bernardi for his excellent work and collaboration.

\section{Disclosure Statement}

All the authors declare that they have no conflicts of interest or relationships with industry relevant to this work.

\section{References}

1 Brivet FG, Kleinknecht DJ, Loirat P, et al: Acute renal failure in intensive care units causes, outcome, and prognostic factors of hospital mortality; a prospective, multicenter study. French Study Group on Acute Renal Failure. Crit Care Med 1996;24:192198.

2 Kellum JA: Acute kidney injury. Crit Care Med 2008;36(4 suppl):S141-S145.

-3 Liano F, Pascual J: Epidemiology of acute renal failure: a prospective, multicenter, community-based study. Madrid Acute Renal Failure Study Group. Kidney Int 1996;50: 811-818.

4 Uchino S, Kellum JA, Bellomo R, et al: Acute renal failure in critically ill patients: a multinational, multicenter study. JAMA 2005;294: 813-818.
Srisawat N, Lawsin L, Uchino S, et al: Cost of acute renal replacement therapy in the intensive care unit: results from the Beginning and Ending Supportive Therapy for the Kidney (BEST Kidney) study. Crit Care 2010; 14:R46.

6 Mehta RL, McDonald B, Gabbai FB, et al: A randomized clinical trial of continuous versus intermittent dialysis for acute renal failure. Kidney Int 2001;60:1154-1163.

7 Canaud B, Bosc JY, Leray H, et al: Microbiological purity of dialysate for on-line substitution fluid preparation. Nephrol Dial Transplant 2000;15(suppl 2):21-30.

$\checkmark 8$ Leblanc M, Moreno L, Robinson OP, et al: Bicarbonate dialysate for continuous renal replacement therapy in intensive care unit patients with acute renal failure. Am J Kidney Dis 1995;26:910-917.
9 Teo BW, Demirjian S, Meyer KH, et al: Machine-generated bicarbonate dialysate for continuous therapy: a prospective, observational cohort study. Nephrol Dial Transplant 2007;22:2304-2315.

10 Clinical Laboratory Standard Institute: Blood Gas Analysis and Related Measurements Approved Guideline, ed 2. Wayne, CLSI, 2009, C46-A2.

11 Alloatti S, Bolasco P, Canavese C, et al: Guidelines on water and solutions for dialysis. Italian Society of Nephrology (in Italian). G Ital Nefrol 2005;22:246-273.

12 Association for the Advancement of Medical Instrumentation: Dialysate for Hemodialysis, ANSI/AAMI RD52. Arlington, Association for the Advancement of Medical Instrumentation, 2004. 
13 Ledebo I, Nystrand R: Defining the microbiological quality of dialysis fluid. Artif Organs 1999;23:37-43.

14 US Department of Health and Human Service, Public Health Service, Food and Drug Administration: Guideline on validation of the Limulus Amebocyte Lysate Test as an end-product endotoxin test for human and animal parenteral drugs, biological products, and medical devices. Rockville, US Department of Health and Human Services, Public Health Service, Food and Drug Administration, 1987.

15 US Pharmacopeial Convention: $<85>$ BacterialEndotoxinsTest.USP262003;NF21(suppl. 2).
16 Woese CR: Bacterial evolution. Microbiol Rev 1987;51:221-271.

-17 Woese CR, Stackebrandt E, Macke TJ, et al: A phylogenetic definition of the major eubacterial taxa. Syst Appl Microbiol 1985;6: 143-151.

18 Weisburg WG, Barns SM, Pelletier DA, et al: 16S ribosomal DNA amplification for phylogenetic study. J Bacteriol 1991;173:697-703.

19 Lane DJ, Pace B, Olsen GJ, et al: Rapid determination of $16 \mathrm{~S}$ ribosomal RNA sequences for phylogenetic analyses. Proc Natl Acad Sci USA 1985;82:6955-6959.
20 International Organization for Standardization: Quality of dialysis fluid for haemodialysis and related therapies. ISO 11663:2009. 21 Maccariello E, Dalboni MA, Draibe SA, et al: Effects of customized bicarbonate buffered solutions for continuous renal replacement therapies on polymorphonuclear leukocytes function and viability. Artif Organs 2004;28: 571-576.

22 Maccariello E, Rocha E, Dalboni MA, et al: Customized bicarbonate buffered dialysate and replacement solutions for continuous renal replacement therapies: effect of crystallization on the measured levels of electrolytes and buffer. Artif Organs 2001;25:870875 